\title{
THE INFLUENCE OF PRODUCT PACKAGING DESIGN, PRODUCT MATERIALS, SHOP SERVICE ON BUYING DECISIONS AL INSAN ELEMENTARY SCHOOL BEKASI CITY
}

\author{
Dewi Rahmawaty ${ }^{1,2}$ Nadiroh$^{2}$, Achmad Husen², Ahman Sya ${ }^{2}$, Sunaryo ${ }^{2}$, Agung Purwanto ${ }^{2}$ \\ ${ }^{1}$ Sekolah Tinggi Desain Interstudi \\ ${ }^{2}$ Universitas Negeri Jakarta \\ Correspondence email: dewi.rahmawaty@yahoo.com
}

\begin{abstract}
This study aims to determine the effect of the uniqueness of product packaging design on our purchasing decisions at SDIT Al Insan Bekasi City. The samples of this study were students of SDOT AlInsan, the technique used was descriptive analysis with a total of 30 respondents. The results of data analysis and hypothesis testing show that the design of product packaging, product materials and service stalls has a significant effect on the buying decisions of SDIT Al Insan students and is able to increase students' buying interest.
\end{abstract}

Keywords:

Product Packaging Design, Product Material, Food Stalls, Buying Decisions, Student Purchasing Decisions.

\section{ABSTRAK}

Penelitian ini bertujuan untuk mengetahui pengaruh keunikan desain kemasan produk terhadap keputusan membeli siswa SDIT Al Insan Kota Bekasi. Sampe dari penelitian ini adalah siswa siswi SDIT Al-Insan, teknik yang digunakan adalah analisis deskriptif dengan jumlah sampel zo orang responden. Hasil analisis data dan pengujian hipotesis menunjukan bahwa desain kemasan produk, material produk dan pelayanan warung berpengaruh signifikan terhadap keputusan membeli siswa SDIT Al-Insan dan mampu meningkatkan minat pembelian siswa.

Kata Kunci:

Desain Kemasan Produk, Material produk, Pelayanan Warung, Keputusan membeli, keputusan membeli siswa

\section{A. PENDAhuluan}

Sekolah Dasar Al Insan Kota Bekasi merupakan salah satu Sekolah Dasar yang berada di Kota Bekasi tepatnya di Jalan Agus Salim nomor 160. SDIT Al Insan merupakan salah satu dari ratusan SD yang ada di Kota Bekasi. Sekolah Dasar atau SD merupakan jenjang paling dasar dalam pendidikan formal di Indonesia. Di Indonesia anak usia SD dimulai dari usia 7 sampai 12 tahun. Jenjang Pendidikan SD dilaksanakan selama 6 tahun, Lulusan SD nantinya dapat melanjutkan ke tingkat yang lebih tinggi yaitu Sekolah Lanjutan
Tingkat Pertama (SLTP). Di masa SD umumnya menjadi masa anak anak paling akhir, sehingga mereka masih senang dengan bermain dan berkelompok.

Kegiatan Belajar mengajar di SDIT AL INSAN memiliki jam istirahat dua kali yaitu jam istirahat pertama di jam sembilan tiga puluh dan kedua di jam dua belas bersamaan dengan jam sholat. Biasanya mereka akan langsung ke kantin untuk membeli jajanan. Banyaknya produk jajanan dari berbagai merk dengan aneka desain kemasan pada 
produk tersebut, menjadi daya Tarik tersendiri bagi siswa SD untuk.

Strategi pengemasan untuk meningkatkan jumlah penjualan menjadi strategi marketing dari sejumah produsen. Di Kota Bekasi saat ini banyak bermunculan pengusaha baru atau pedagang di masa pandemic. Menurut Kotler dan Amstrong (2012) "packaging involves designing and producing the container or wrapper for a product" bahwa kemasan melibatkan proses kegiatan mulai dari produksi, yang digunakan sebagai perlindungan desain.

Desain kemasan produk ada untuk dapat mengarahkan pembeli untuk akhirnya memutuskan membeli produk tersebut. Hermawan Kertajaya mengatakan dahulu kala kemasan produk digunakan untuk melindungi barang yang akan dijual, tetapi saat ini perkembangan zaman dan perubahan zaman maka produk atau barang yang akan dijual yang artinya kemasan desain produk yang melindungi barang dagangan itu tersebut. Ada banyak pilihan material kemasan desain mulai dari berbahan plastik seperti plastik bening, mika, juga ada dari bahan kertas seperti kardus bahkan sampai kaca.

Jajanan yang ada di SDIT Al-Insan adalah jenis siap saji yang akan langsung dinikmati oleh siswa ketika mereka sedang beristirahat. Jenis jajanan yang ada di SDIT Al-Insan seperti minuman dan makanan ringan serta menu nasi dalam kemasan kecil.

Berdasarkan uraian di atas maka perlu di adakan penelitian dengan judul "PENGARUH KEUNIKAN DESAIN KEMASAN PRODUK TERHADAP KEPUTUSAN MEMBELI SISWA SDIT AL INSAN BEKASI"

\section{Keputusan Membeli}

Keputusan pembelian merupakan dimana individu mengevaluasi berbagai pilihan dan memutuskan pilihan pada suatu produk dari sekian banyak pilihan. Menurut Kotler dan Amstrong (2014), keputusan pembelian adalah tahap dalam proses pengambilan keputusan pembeli di nana konsumen benar benar membeli.

Menurut Schiffman dan KAnuk (2014) keputusan pembelian didefinisikan sebagai sebuah pilihan dari dua tahun lebih alternative pilihan. Menurut Tjiptono (2012) keputusan pembelian adalah sebuah proses dimana konsumen mengenal masalahnya, mencari informasi mengenai produk atau merek tertentu dan mengevaluasi secara baik masing masing alternative tersebut dapat memecahkan masalahnya, yang kemudian mengarah kepada keputusan pembelian.

Dari pengertian tersebut dapat disimpulkan keputusan pembelian merupakan sebuah proses pengambilan keputusan yang diawali dengan pengenalan masalah kemudian mengevaluasinya dan memutuskan produk yang paling sesuai dengan kebutuhan.

Faktor yang mempengaruhi keputusan membeli menurut Tjiptono (2012) adalah ikatan emosional yang terjalin antara pelanggan dan produsen setelah pelanggan menggunakan produk dan jasa dari perusahaan dan mendapati bahwa produk atau jasa tersebut memberi nilai tambah. Dimensi nilai terdiri dari 4 , yaitu :

1. Nilai emosional, utilitas yang berasal dari perasaan atau afektif atau emosi positif yang ditimbulkan dari mengkonsumsi produk. Jika konsumen mengalami perasaan positif pada saat membeli atau 
menggunakan suatu merek, maka merek tersebut memberikan nilai emosional. Pada intinya nilai emosional berhubungan dengan perasaan, yaitu perasaan positif apa yang akan dialami konsumen pada saat membeli produk.

2. Nilai social, utilitas yang didapat dari kemampuan produk untuk meningkatkan konsep diri sosial konsumen. Nilai sosial merupakan nilai yang dianut oleh suatu konsumen, mengenai apa yang dianggap baik dan apa yang dianggap buruk oleh konsumen

3. Nilai Kualitas, utilitas yang didapat dari produk karena reduksi biaya jangka pendek dan biaya jangka panjang

4. Nilai Fungsional adalah nilai yang diperoleh dari atribut produk yang memberikan kegunaan (utility) fungsional kepada konsumen nilai ini berkaitan langsung dengan fungsi yang diberikan oleh produk atau layanan kepada konsumen

2. Faktor Faktor Desain Kemasan Produk

Kemasan yang baik dan akan digunakan semaksimal mungkin dalam pasar harus mempertimbangkan dan dapat menampilkan beberapa faktor, antara lain sebagai berikut,

a. Faktor Keamanan

Kemasan harus melindungi produk terhadap berbagai kemungkinan yang dapat menjadi penyebab timbulnya kerusakan barang, dari cuaca sinar matahari kuman.

b. Faktor Ekonomi

Perhitungan biaya produksi yang efektif termasuk pemilihan bahan sehingga biaya tidak melebihi proporsi manfaatnya. Seperti produk isi ulang.

c. Faktor Pendistribusian

Kemasan harus mudah didistribusikan dari pabrik ke distributor atau pengecer sampai ke tangan konsumen. Di tingkat distributor, kemudahan penyimpanan dan pemajangan perlu dipertimbangkan. Bentuk dan ukuran kemasan harus direncanakan dan dirancang sedemikian rupa sehingga tidak sampai menyulitkan peletakan tidak sampai menyulitkan peletakan di rak atau tempat pajangan.

d. Faktor Komunikasi

Sebagai media komunikasi kemasan menerangkan dan mencerminkan produk, citra merek, dan juga bagian dari produksi dengan pertimbangan mudah dilihat, dipahami dan diingat. Misalnya karena bentuk kemasan yang aneh sehingga produk tidak dapat diberdirikan.

e. Faktor ergonomic

Pertimbangkan agar kemasan mudah dibawa atau dipegang, dibuka dan mudah diambil sangatlah penting. Pertimbangan ini selalu mempengaruhi bentuk dari kemasan itu sendiri juga mempengaruhi kenyamanan pemakai produk atau konsumen. Contohnya, bentuk botol minyak goreng Tropical yang pada bagian tengahnya diberi cekungan dan tekstur agar mudah dipegang dan tidak licin bila tangan pemakainya terkena minyak.

f. Faktor estetika

Keindahan padan kemasan merupakan daya Tarik visual yang mencakup pertimbangan penggunaan warna, bentuk, merk atau logo, ilustrasi, huruf, tata letak atau layout, 
dan mascot. Tujuannya adalah untuk mencapai mutu daya Tarik visual secara optimal.

g. Faktor Identitas

Secara keseluruhan kemasan harus berbeda dengan kemasan lain, memiliki identitas produk agar mudah dikenali dan dibedakan dengan produk produk yang lain.

h. Faktor Promosi

Kemasan mempunyai peranan penting dalam bidang promosi, dalam hal ini kemasan berfungsi sebagai silent sales person. Peningkatan kemasan dapat efektif untuk menarik perhatian konsumen baru.

i. Faktor lingkungan

Kita hidup di dalam era industri dan masyarakat yang berpikiran kritis. Dalam situasi dan kondisi seperti ini, masalah lingkungan tidak dapat terlepas dari pantauan kita. Trend dalam masyarakat kita akhir akhir ini adalah kekhawatiran mengenai polusi, salah satunya pembuangan sampah. Salah satunya yang pernah menjadi topik hangat adalah styrofoam. Sekarang ini banyak perusahaan yang menggunakan kemasan kemasan yang ramah lingkungan.

\section{Material Kemasan}

Secara umum sebuah produk dapat kita klasifikasi sebagai produk benda padat, produk benda cair dan produk granule (Pellet). Dalam penangananya setiap bahan memiliki perbedaan, namun secara garis besar memiliki kesamaan yang harus diperhatikan misalnya agar tahan cahaya, udara sehingga tidak mudah rusak. Bahan yang dapat digunakan oleh kebanyakan seperti plastic, aluminium, stryform, kaca dan kertas/ dus.
Bahan plastic berasal dari minyak bumi dan diolah untuk menjadi bentuk dan satuan senyawa yang diinginkan dengan cara laminasi, ekstrusi dan kopolimerasi (syarief, 1989).

Aluminium berasal dari mineral bumi, karakter dari aluminium adalah tahan terhadap lingkungan asam, tidak beracun dan tahan minyak. Bahan ini alternative dari bahan plastic dan kertas sebagai alternative yang biasa dipakai pengolah jajanan kuliner sebagai pembungkus makanannya.

\section{Pelayanan Warung}

Pelayanan akan mempengaruhi kepuasan pada pelanggan, seringkali konsumen atau pembeli akan merasa puas senang jika pelayanan yang diberikan prima yaitu sikap ramah cepat dan tanggap. Begitupun dengan melayani pembeli siswa SD yang memiliki perbedaan karakter dari konsumen usia dewasa. Mereka cenderung banyak bertanya dengan nilai transaksi yang kecil, bahkan banyak memilih walau kadang akhirnya memilih produk awalan. Agar sebuah warung diminati oleh pembeli harus memenuhi pelayanan yang prima.

Kepuasan pembeli memiliki pengaruh baik dijangka panjang serta jangka pendek, bisa mempengaruhi kemajuan dari warung tersebut. Pembeli akan cenderung ingin membeli dan kembali lagi membeli karena puas dari sebuah service quality karena kenyaman saat belanja di harga, dilayani dan dijawab semua pertanyaan terkait produk yang akan dibeli.

Menurut Kotler I 1997 :50) kualitas harus dirasakan oleh pembeli dimulai dengan adanya kebutuhan pembeli dan diakhiri dengan terpenuhinya kebutuhan pembeli tersebut. Karena hal ini, pemilik 
warung harus pandai dalam memenangkan minta pembeli. Warung di SD paling banyak berjualan makanan dan minuman ringan sebagai pemenuhan kebutuhan pangan di saat jam istirahat sekolah.

\section{B. METODE PENELITIAN}

Penelitian menggunakan data primer yang diperoleh dari subjek penelitian dengan cara membagikan kuesioner. Operasionalisasi variabel adalah variabel bebas (Independent variable) Desain Kemasan Produk (X1), Material kemasan (X2) , Pelayanan Warung $\left(\mathrm{X}_{3}\right)$ Variabel Terikat (Dependent Variable) Keputusan Membeli (Y).

Uji validitas akan dilakukan untuk menemukan nomor yang valid atau tidak valid dengan tabel $r$ product moment.

Kriteria penilaian uji validitas adalah :

1. Apabila rhitung $>\mathrm{r}$ tabel, maka item kuesioner tersebut valid.

2. Apabila rhitung < rtabel maka kuesioner tidak valid.

Cara pengujian reliabilitas pada penelitian ini adalah menggunakan koefisien Alpha Cronbach. Perhitungan uji validitas dan reliabilitas dalam penelitian ini menggunakan program SPSS.

Parameter yang dihasilkan akan menggambarkan respon $\mathrm{Y}$ (variable dependent) atas perbedaan nilai variabel X. Ordinary least Square (OLS) bentuk persamaan dalam penelitian ini adalah $\mathrm{Y}=\alpha+\beta_{1} \mathrm{X}_{1}+\beta_{2} \mathrm{X}_{2}+\beta_{3} \mathrm{X}_{3}+$ e. tanda parameter $\beta$ menggambarkan arah hubungan antara variabel dependen dan independen. Jika nilai $\beta+$ maka hubungan $X$ dan $Y$ searah, semakin tinggi $\mathrm{X}$ maka $\mathrm{Y}$ juga semakin tinggi, jika nilai $\beta$ - maka hubungan $X$ dan $Y$ tidak seraha, semakin tinggi $\mathrm{X}$ tidak serta merta diikuti oleh Y.

Uji tanda menggunakan dua parameter $\beta$, jika $\beta$ positif bahwa variabel $X$ dan $Y$ Linier kenaikan $X$ akan diikuti oleh $Y$, jika $\beta$ negative bahwa variabel $X$ dan $Y$ tidak linier atau searah, kenaikan $\mathrm{X}$ tidak akan diikuti oleh Y. Untuk uji t bertujuan untuk variabel bebas dalam penelitian ini yaitu desain kemasan produk, bentuk kemasan, pelayanan warung secara parsial.

1. Ho: $\beta_{1}, \beta_{2}, \beta_{3}=0$, tidak ada pengaruh yang signifikan antara ketiga variabel bebas kepada keputusan membeli siswa SD

2. Ha: $\beta_{1}, \beta_{2}, \beta_{3} \neq 0$, ada pengaruh yang signifikan antara ketiga variabel bebas kepada keputusan membeli siswa SD.

Uji ketepatan model, digunakan untuk mengukur ketepatan variabel bebas kepada variable terikat dengan menggunakan uji F dan Koefisien Determinasi (R2). Nilai koefisien determinasi adalah antara nol dan satu. Nilai yang mendekati satu berarti variabel variabel bebas memberikan hampir semua informasi yang dibutuhkan untuk memprediksi variasi variabel terikat (Ghozali, 2011 : 97). Uji F digunakan untuk mengukur variabel bebas terhadap variabel terikat apakah berpengaruh secara bersama sama, Ho : $\beta_{1}, \beta_{2}, \beta_{3}=0$ berarti tidak ada pengaruh signifikan, Ha : Ha : $\beta_{1}, \beta_{2}, \beta_{3} \neq$ o berarti ada pengaruh signifikan.

Uji asumsi klasik digunakan sebelum regresi linear berganda, uji asumsi meliputi uji normalitas, uji multikolinearitas. Uji normalitas menggunakan Test Kolmogorov Smirnov, jika asymp sig signifikan dibawah 0,05 berarti mempunyai perbedaan yang 
signifikan dan tidak normal, apabila signifika di atas 0,05 berarti data yang diuji norma. Uji multikolinearitas digunakan untuk menguji adanya hubungan korelasi antara variabel bebas independen Uji heteroskedastisitas digunakan untuk menguji di dalam model regresi terjadi ketidaksamaan varian dari residual satu pengamatan varians dari residual satu pengamatan ke pengamatan yang lain (Ghozali)

\section{PEMBAHASAN}

Hasil analisis data dengan metode regresi linear berganda menghasilkan persamaan sebagai berikut :

$\mathrm{Y}=4,8766+0,186 \mathrm{X}_{1}+0,408 \mathrm{X}_{2}+0,360 \mathrm{X}_{3}$

$+\mathrm{e}$

thitung $=(2,378)(2,088)(2,749)(2,375)$

Tabel 1. Hasil Uji Regresi Linear

Berganda

\begin{tabular}{|c|c|c|c|}
\hline $\begin{array}{l}\text { Paramete } \\
\text { r }\end{array}$ & $\begin{array}{l}\text { Koefisie } \\
\text { n } \\
\text { Regresi }\end{array}$ & $\begin{array}{l}\text { THitun } \\
\mathrm{g}\end{array}$ & Sig \\
\hline Konstanta & 4,876 & 2.378 & 0,001 \\
\hline $\begin{array}{l}\text { Design } \\
\text { Kemasan } \\
\text { Produk }\end{array}$ & 0,186 & 2,088 & 0,039 \\
\hline $\begin{array}{l}\text { Material } \\
\text { kemasan }\end{array}$ & 0,408 & 2,749 & 0,007 \\
\hline $\begin{array}{l}\text { 'Pelayana } \\
\text { n warung }\end{array}$ & 0,360 & 2,375 & 0,020 \\
\hline F statistic & 29.440 & $\begin{array}{l}\mathrm{R} \\
\text { Square }\end{array}$ & 0,462 \\
\hline $\begin{array}{l}\text { Probabilit } \\
\text { y }\end{array}$ & o & & \\
\hline
\end{tabular}

Berdasarkan hasil fungsi persamaan diatas, dapat diartikan bahwa nilai koefisien regresi variabel desain kemasan produk, material kemasan dan pelayanan warung berpengaruh positif terhadap keputusan membeli sisa SD, dimana semakin tinggi persepsi pembeli terhadap variabel desain kemasan produk, material kemasan, pelayanan warung maka semakin tinggi keputusan membeli pembeli siswa SDIT.

\section{KESIMPULAN}

Berdasarkan hasil perhitungan dapat disimpulkan sebagai berikut :

1. Desain kemasan produk berpengaruh terhadap keputusan membeli pembeli, sehingga hipotesis pertama bahwa desain kemasan produk berpengaruh terhadap keputusan membeli siswa SD terbukti. Penjual mengemas produk dengan desain yang menarik sehingga menimbulkan keputusan membeli.

2. Bahwa kemasan berpengaruh secara signifikan terhadap keputusan membeli Siswa SD, sehingga hipotesis kedua bahwa kemasan berpengaruh signifikan terhadap keputusan membeli siswa SD. Produk yang dijual di lingkungan SD menggunakan kemasan yang bervariasi mulai dari plastic, paper metal seperti snack snack yang membuat produk diminati oleh siswa SD.

3. Pelayanan warung berpengaruh signifikan terhadap keputusan membeli siswa SD, sehingga hipotesis terhadap keputusan membeli terbukti. Bentuk layanan yang ramah, cepat dan menjawab semua pertanyaan dari siswa SD menjadikan produk diminati untuk dibeli oleh siswa SD.

Pengaruh desain kemasan produk, bentuk kemasan dan pelayanan warung memiliki dampak positif terhadap keputusan membeli siswa SD untuk meningkatkan hasil penjualan disarankan beberapa hal sebagai berikut :

1. Desain kemasan produk yang saat ini ada di sekolah SD dapat dibuat dalam 
berbagai kemasan ukuran, mulai dari kemasan kecil sedang dan besar. Karena siswa SD bervariasi mulai dari kelas kecil dan kelas besar yang memiliki kebutuhan berbeda beda. Desain kemasan merupakan salah satu hal yang dapat menarik keinginan pembeli untuk membeli suatu produk. Fungsi awal kemasan yang hanya sebagai pembungkus produk, dengan pertimbangan keindahan maka desain produk dibuat lebih estetis.

2. Material kemasan, dengan material kemasan yang tepat akan melindungi isi produk yang dijual di pasaran terutama di SD. Agar tetap terjaga kualitas dan estetika dari produk yang akan dijual. Pemilihan material kemasan yang sesuai dengan produk akan meningkatkan mutu dari produk, sehingga pembeli akan langsung memilih produk tersebut tanpa ragu ragu.

Material kemasan produk yang tepat memberi motif pembeli untuk memilih produk material kemasan yang tepat, desain yang visual, citra yang dikesankan terlihat dari apa yang dilihat. Untuk itu material kemasan produk harus mampu menciptakan daya Tarik bagi konsumen, kemasan yang menarik mampu meningkat kan keputusan membeli terutama siswa SD yang menyukai warna warni yang mencolok. Daya Tarik warna dan keunikan desain produk yang mempengaruhi siswa SD memilih produk tersebut dari sekian banyak yang ada.

3. Pelayanan Warung

Pelayanan warung yang ramah, cepat dan menjawab semua pertanyaan akan meningkatkan hasil penjualan secara maksimal dan meningkatkan keputusan membeli siswa SD.

Keramahan penjual kepada siswa SD saat melayani, menjawab semua pertanyaan saat siswa SD membeli dan kecepatan saat melayani siswa SD membeli dapat meningkatkan minat siswa SD.

\section{DAFTAR PUSTAKA}

Engel, J Roger D Blackwell and Paul W Miniard, 2008. Perilaku Konsumen : Alih Bahasa : Budyanto. Jilid I. Jakarta: Binarupa Aksara Publisher

Ferdinand A T. 2002 Structural Equation Modeling dalam penelitian Manajemen" Badan Penerbit Universitas Diponegoro, Semarang.

Ghani, Usman dan Kamal Yasir. 2010. The Impact Of Instore Stimull On The Impulse Purchase Behaviour Of Consumer In Pakistan.Interdisciplinary Journal Of Contemporary Research In Business Vo2, 8, 155-339.

Isen, Alice M. 1984. The influence Of Positive affect on decision organization in NA, Advance in Consumer Research Vol 11.Eds Thomas C Kinnear Provo, UT. Association For Consumer Research pp 534-537

Karbasivar Alireza dan Yarahmadi Hasti, 2011 Evaluasting Effective Factor On Consumer Impulse Buying Behaviour Asian Journal Of Business Management Studies 2(4) : 174-181, 2011 ISSN 2222-1387

Kaltcheva. V dan B Weits(2006) When Should a Retailer Create an Exciting Store

Kim H. 2005 Consumer profiles of apparel product involvement and values 
journal of Fashion Marketing and Management Vol 9 No 2 pp 207-20

Kotler, Philip Gary Armstrong, 2008, Prinsip prinsip pemasaran, Edisi 12 Jilid 1 Erlangga, Jakarta

Klimchuck, Marrianne Rosner and Krasovec Sandra A 2007. Desain Kemasan Erlangga, Jakarta

Liang Y P Liang JL dan Duan YS 2008. Relationship between Consumer Information Exposure, Product
Knowledge and Impulse Purchasing Behaviour. An Empirical Analysis International Journal of Management. Vol 25 No 3 pp 418430

Levy, Michael Barton A weitz 2007 Impulse Buting. Tantangan baru pemilik merek. Marketing Jakarta 